\title{
Reflecting on Clinical Training Instruction: Improving New Instructors' Capabilities
}

\author{
By Hiroko Tokumoto ${ }^{*}$ \\ Katsura Goto ${ }^{+}$ \\ Makiko Arai ${ }^{\ddagger}$
}

\begin{abstract}
Novice-nursing faculties face difficulties during clinical education. Clinical education is similar to cognitive apprenticeship, a program that helps nursing students develop as nurses. To verify the efficacy of a clinical education model as a reflection model that strengthens the competency of novice-nursing faculties to teach clinical practice. Two studies were conducted for verification. We examined opinions and thoughts on the practices of new nursing faculties by using cases as data, and subsequently, we conducted a two-year reflection on these cases. We performed an inductive analysis by using the case-study descriptions as outcome data for the new nursing faculties in question. Consent was obtained from the ethics committee of the authors' affiliated university. From the 14 cases, many accounts provided descriptions of situations only, with no descriptions of professors or students' studies. Novice faculties initially focused on the students' insufficient abilities, problematic behavior and inexperienced observations and responded emotionally. The qualitative inductive analysis results clarified that clinical education was conducted based on four perspectives and five approaches, thus identifying the conditions of the education and students.
\end{abstract}

Keywords: Clinical education model, Novice faculty, Reflection, Case studies, Clinical education competency

\section{Introduction}

Many novice-nursing faculties face difficulties in instructing clinical practice (Ishida 2010, Ito and Omachi 2009). It is necessary to formulate countermeasures for dealing with these issues (Ministry of Health, Labor and Welfare 2010). The affiliated institution's faculty development (FD) is entrusted with problem resolutions for novice-nursing faculties (JANPU $2011^{1}$ ). However, no research clarifies how novice faculties should resolve problems and acquire educational competency. Donald Schön (1983) states that professional competency is developed through reflection. However, the main question for nursing faculties is what to reflect on and how to reflect in order to develop clinical educational competency. After Usui published "Usui's Theory" based on Florence Nightingale's writings, case studies were conducted at research meetings based on Usui's theory with the aim to develop clinical educational competency. The results were published (Usui 1991a). Furthermore, studies relating to the clinical educational competency of nurses

\footnotetext{
* Professor, Saitama Prefecture University, Japan.

${ }^{\dagger}$ Associate Professor, Saitama Prefecture University, Japan.

\$ Instructor, Saitama Prefecture University, Japan.

${ }^{1}$ FD Guidelines for Young Nursing Instructors: Seeking to Improve the Quality of Nursing Education (2011), in The 23rd Annual Conference for Improving Nursing Education of the Japan Association of Nursing Programs in Universities. Retrieved from goo.gl/OsgyhL.
} 
and nursing faculties that participated in the case study research meetings (Wazumi 1996, Ogasawara 1994, Tokumoto 1998) revealed an improvement in their clinical educational competency. The authors have continued these case study meetings for many years, supposing that reflection by means of cases where nursing faculties faced difficulty in clinical education could develop their clinical educational competency. These case studies have reported an expansion of the situational awareness of nursing faculties that continuously participate in reflection meetings (Tokumoto 2013).

We report on two studies concerning the efficacy of clinical educational models (Usui 1991b) as a framework for reflecting on difficult cases and conditions and the clinical educational competency of new nursing faculties.

\section{Background}

Usui, who retheorized the essence of nursing based on Florence Nightingale's works, published kagakuteki kangoron (Usui 1974). According to Usui, nurses study average human beings and general health disorders and understand their commonality with the patient as a human being and between human beings in their affliction with illnesses. Usui also demonstrates the logical thinking of professional nurses concerning the support that is necessary for creating healthier lives for patients. Furthermore, the theory presents thoughts on the development of a methodological nursing process. Usui also provides a clinical education model for transforming students into professionals by means of clinical education that represents both the students' learning process and the instructors' instruction process (Usui 1991b). This model represents the process of studying according to a professional way of thinking and expressing one's self as a nurse while communicating about one's nursing views. Fellow nurses deal with patients under the premise that clinical education is learning through trial and error, a method whereby students nurse patients by using what they have learned. Figure 1 shows this model.

Furthermore, case studies that focus on training clinical instructors (also known as reflective case studies) use a clinical training model that highlights clinical training instruction characteristics. The first part of this model explains the characteristics of the target patient and identifies the necessary nursing procedures. Secondly, the model explains the students' characteristics on the basis of their behavior and documentation, that is, how they think about and act toward patients. The third part of the model reflects on how the nursing process between student and patient is progressing. Fourthly, the model explains the instructional process whereby the instructor's thoughts and judgment are communicated so that the students' actions nurse patients. The fifth part of the model clarifies the characteristics of the clinical instructor and highlights the characteristics of the clinical training instructions as stated in the case. In short, when nurses applied this theoretical model to their case studies, the patients' image developed and the structure of difficult scenarios was clarified. Moreover, one might say that the clarification of this structure enabled the 
depiction of the patients' health status as well as trends in nursing. This study indicates that the patients' image developed as interactions between participating fellow nurses and that the patients progressed in case studies that applied Usui's theory; nurses who could depict the patients' conditions in multifarious ways could easily understand the meaning of the patients' personal experiences from their perspectives, and as a result nurses could easily describe trends in nursing. The question remains what kind of learning was achieved by new nursing instructors who participated in the case study meetings that made use of this theoretical model. We will examine the perspectives and skills gained through case studies and the state of the educational competency of novice-nursing faculties on the basis of the following two studies.

Figure 1. Clinical Training Model (Usui 1991b)

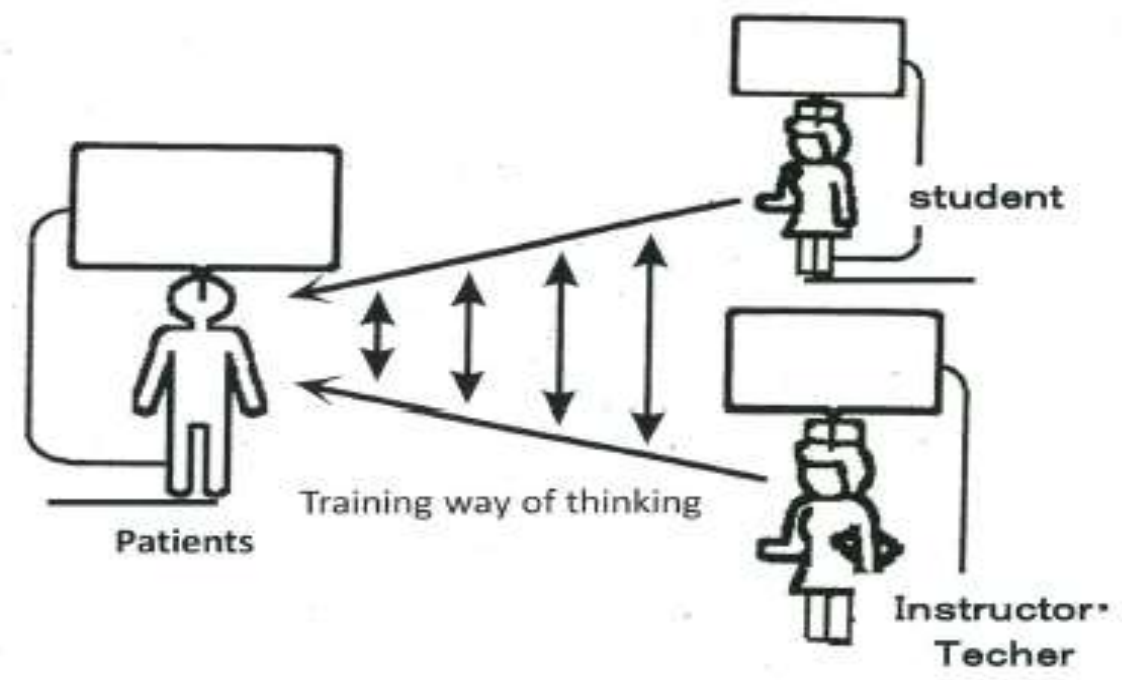

Figure 1 clinical training model

models (Usui 1991)

\section{Study 1}

Purpose

The studies purpose is to examine the state of the novice-nursing faculties' competency in clinical education by considering their thoughts and techniques concerning scenarios where instruction is difficult.

\section{Methods}

$\underline{\text { Target }}$

The target participants were new instructors (in this study, new instructors are those who have completed their nursing instruction training and who have been instructing for three years or less). Term: 2012 2014 
Data Collection Methods

Professional extension lectures for new nursing instructors were held. As a condition of participation, instructors introduced cases where they had faced difficult situations; they were asked to describe these situations in process records. These process records were used as data.

\section{Data Analysis Methods}

From the presented cases, we obtained descriptions of perspectives related to learning (characteristics of students, individualized plans, learning evaluations) and perspectives related to instruction (educational goals, learning goals, patient characteristics) while referencing the survey frameworks for new instructors devised by Sato et al. (1990). We also obtained descriptions of facts that were focused on, participants' thoughts on these facts, and the steps they took as a result. We conducted our analysis of the instructors' thoughts on impressions (impressions of actions whose basis and reasons were not described) and inferences (impressions and evaluations accompanied by reasons and justifications; conjectures on students' intentions and thoughts, their behavior, and the intent of statements). The descriptions were classified as part of the procedures.

\section{Results}

There were 14 participants. Four participants were in their 30 s, eight in their 40s, and two in their 50s. In terms of instructor experience, four participants had less than one year of experience, five had one year, four had two years, and one had three years. Regarding perspectives related to instruction, three participants described learning goals and patient conditions, one described only patient conditions, and 10 provided no descriptions related to instruction. Regarding perspectives related to learning, only one participant described student characteristics, individualized plans, and learning evaluations. One participant described student characteristics and individualized plans, four described only student characteristics, and eight provided no descriptions of perspectives on learning. Altogether, eight participants did not describe their views on either instruction or learning. Next, the instructors focused on the students' behavior as facts from the cases and all instructors described worrisome behavior. In terms of the students' behavior, all instructors recalled their thoughts concerning "proper behavior and rules", "preliminary instruction", "planned behavior", and "the condition of the patient", and only provided "impressions of the students' actions". No descriptions were given that conjectured on or made inferences about students' actions or the meaning of their statements. In these situations, we observed the following actions: confirmation of behavior (10), identification of problems (9), giving direction (6), demanding an explanation (4), and handling the nursing procedure by themselves (3) (Tables 1, 2, 3). 
Table 1. Perspectives Related to Learning

\begin{tabular}{|c|c|c|c|}
\hline \multirow{2}{*}{ Participants: } & \multicolumn{3}{|c|}{ perspectives related to learning } \\
\hline & $\begin{array}{c}\text { characteristics of } \\
\text { students }\end{array}$ & $\begin{array}{l}\text { individualized } \\
\text { plans }\end{array}$ & $\begin{array}{c}\text { learning } \\
\text { evaluations }\end{array}$ \\
\hline A & & & \\
\hline B & & & \\
\hline C & o & o & 0 \\
\hline $\mathrm{D}$ & & & \\
\hline E & & & \\
\hline$F$ & 0 & & \\
\hline G & & & \\
\hline $\mathbf{H}$ & o & & \\
\hline 1 & & & \\
\hline 1 & & & \\
\hline $\bar{K}$ & 0 & & \\
\hline 1 & & & \\
\hline M & 0 & & \\
\hline $\mathbf{N}$ & o & o & O \\
\hline
\end{tabular}

Table 2. Perspectives Related to Instruction

\begin{tabular}{|c|c|c|c|}
\hline & \multicolumn{2}{|c|}{ perspectives related to instruction } \\
\hline Participants & $\begin{array}{c}\text { educational } \\
\text { goals }\end{array}$ & $\begin{array}{c}\text { Learning } \\
\text { goals }\end{array}$ & $\begin{array}{c}\text { Patient } \\
\text { characteristics }\end{array}$ \\
\hline A & & 0 & \\
\hline B & & & 0 \\
\hline C & & \\
\hline D & & & \\
\hline E & & & \\
\hline F & & & \\
\hline H & & & \\
\hline I & & & \\
\hline K & & 0 & 0 \\
\hline L & & 0 & 0 \\
\hline M & & & \\
\hline N & & & \\
\hline
\end{tabular}


Table 3. Following Action

\begin{tabular}{|l|c|}
\hline \multicolumn{1}{|c|}{ contents } & describe \\
\hline confirmation of behavior & 10 \\
\hline identification of problems & 9 \\
\hline giving direction & 6 \\
\hline demanding an explanation & 4 \\
\hline handling the nursing procedure by themselves & 3 \\
\hline suggestion & 2 \\
\hline Wait and see & 1 \\
\hline
\end{tabular}

\section{Study 2}

Purpose

To examine the methods and views obtained from approximately two years of case study reflections by new instructors who presented the above cases.

\section{Methods}

The target participants were seven instructors who continued the case studies during a period of two years.

\section{Data Collection Method}

We asked the instructors what they had learned and what had changed. Each instructor wrote a separate answer on a card and these cards were used as data.

\section{Methods of Analysis}

We analyzed the data using an Affinity diagram. In these case studies, the new instructors described their reasons based on clinical education cases (from their process records) where they faced difficulties while leading instruction, and they explained these difficult cases according to their process records. For instance, they explained what they wanted to do, what they were thinking and how they acted, and how they felt about the consequences of their actions. Subsequently, the new instructors were questioned by experienced instructors according to the clinical education model. For instance, questions about students' perspectives, which were an attempt to understand students' characteristics, included: How did you understand the patient's characteristics and how did the students understand the patient's characteristics? What did the students think? How did the students feel because of this? In addition, participants were questioned on training goals, student learning goals, and the relation between student readiness and training goals. Furthermore, they were 
advised by experienced instructors, who participated as facilitators, regarding their understanding of the patients and students on the basis of facts concerning the situation, and how it was possible to progress according to the training goals. Lastly, each instructor presented their realizations and what they had learned from the case studies. Term: $2014 \sim 2015$.

\section{Results}

The data considered in this study comprised 393 cards describing what the new instructors had learned in the case studies, with 30 reflections for the first level, 12 for the second, and five for the third level.

According to what novice faculties learned from the case studies, the following four aspects of understanding students can be determined: Realizing that students lack coordinating capabilities or interpersonal skills in practicing nursing because they have had insufficient life experiences; Realizing that students are unable to handle group behavior and cannot progress quickly in the study of nursing because they have not learned how to study from a nurse's perspective; Understanding the necessity of comprehending the individual and focusing on the experiences behind students' behavior; and Understanding that students become proactive when they understand the necessity of study and how to study. The first aspect changes from focusing on students' inabilities to understanding the causes of their inabilities. The second aspect changes from a nurse's perspective to the perspective of a faculty. Those two lead to the third aspect, and subsequently to the forth aspect (Figure 2).

Figure 2. Things Learned by the Novice instructors from Case Studies (Perspectives on Students)

\begin{tabular}{|c|c|c|c|}
\hline $\begin{array}{l}\text { Change from } \\
\text { focusing on } \\
\text { students' } \\
\text { inabilities to the } \\
\text { understanding of } \\
\text { the causes of } \\
\text { their inabilities }\end{array}$ & \multicolumn{2}{|c|}{$\begin{array}{l}\text { 4. Understanding that students become } \\
\text { proactive when they understand the } \\
\text { necessity of study ang how to study. } \\
\begin{array}{l}\text { 3. Understanding the necessity of } \\
\text { comprohending the individual and } \\
\text { focusing on the experiences } \\
\text { behind students' behavior. }\end{array}\end{array}$} & $\begin{array}{l}\text { Change from a } \\
\text { nurse's } \\
\text { perspective to } \\
\text { the perspective } \\
\text { of a teacher } \\
\text { training nurses }\end{array}$ \\
\hline $\begin{array}{l}\text { 1. Realizing } \\
\text { lack coordin } \\
\text { capabilities } \\
\text { skills in prat } \\
\text { because they } \\
\text { insufficient }\end{array}$ & $\begin{array}{l}\text { lat students } \\
\text { ing } \\
\text { interpersonal } \\
\text { cing nursing } \\
\text { tave had } \\
\text { experiences. }\end{array}$ & $\begin{array}{l}\text { 2. Realizing that b } \\
\text { have not learned } \\
\text { from the nursing } \\
\text { are unable to han } \\
\text { behavior and they } \\
\text { quickly in the stud }\end{array}$ & $\begin{array}{l}\text { use students } \\
\text { to study } \\
\text { pective, they } \\
\text { group } \\
\text { inot progress } \\
\text { f nursing. }\end{array}$ \\
\hline
\end{tabular}

Four aspects of understanding educational practice can be determined according to what was learned from the case studies: Objective views of oneself via reflection, which is a clarification of problems and moves toward 
being proactive in dealing with problems through reflection; Conveying nursing concepts, namely, the relationships that allow the student to understand the patient and get a feel for nursing; Planning education that intentionally follows educational goals and objectives; and Instructive evaluation that can instruct while understanding the limits of instruction. Based on reflection and conformation, the first, second, and third aspects lead to the forth by means of comprehension of the educational knowledge gained at the instructor training course through experience.

Subsequently, those two separate understandings are combined into one. The base line is the objective view of oneself via reflection, which is a clarification of problems and moves toward being proactive in dealing with problems through reflection. Through reflection and confirmation, the two understandings influence each other. One is conveying nursing concepts, namely, the instructor relationship that allows the student to understand the patient and get a feel for nursing. The other understands students, namely, the necessity of understanding students for actualizing education that suits the student. These two lead to planning education, namely, intentional planning to follow educational goals and objectives. To achieve this, novice faculties must reflect and confirm on the base line. These four aspects constitute the comprehension of educational knowledge gained at the instructor training course through experience. Moreover, for those cyclic and reflective items, there is the evaluation of clinical education (Figure 3).

Figure 3. Things Learned from Case Studies (Understanding Educational Practice)

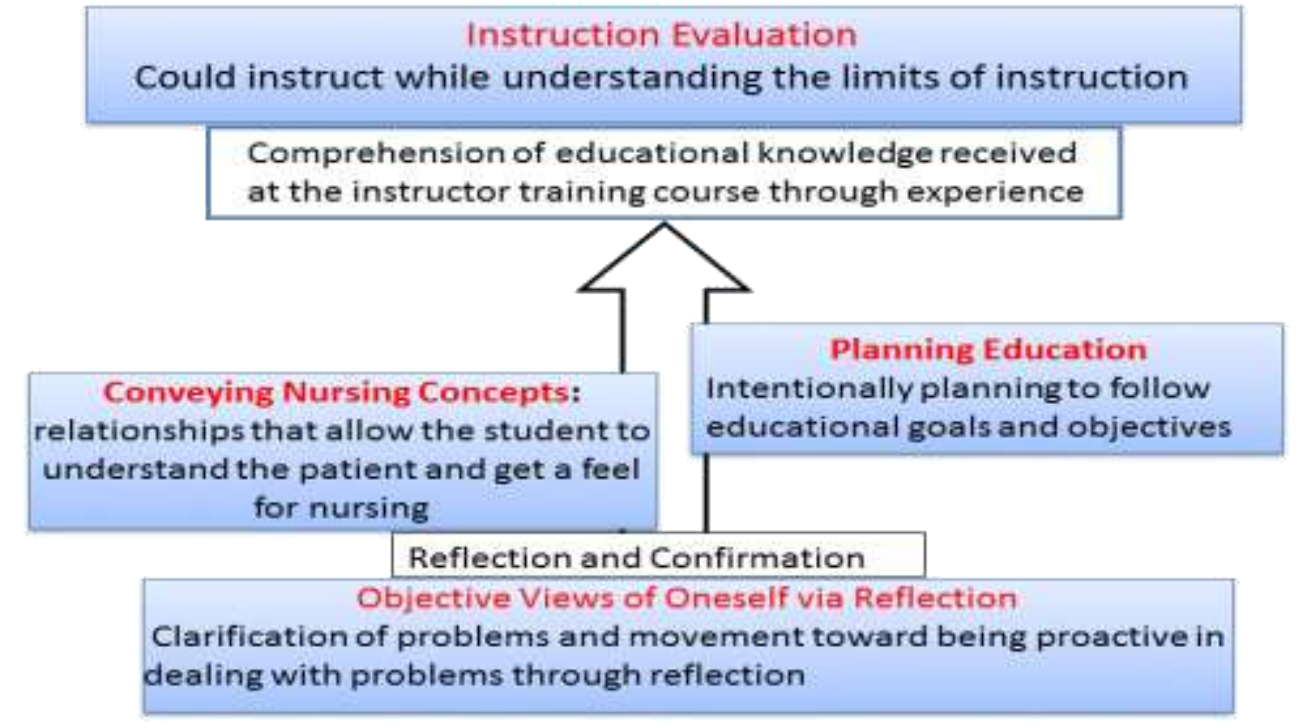

\section{Discussion}

Currently, the use of case studies for new instructors is being supported as a method for the integration of various scholarly insights that can be applied to practical problems of instruction (Lin et al. 2005, Bill 2011 ). Akita states that the 
difficulty faced by new instructors lies in the complexity of educational practice, and suggests that learning through case studies is a way of learning about responses to complexity (Akita 2009). Case studies present opportunities for new instructors to think like professionals. Moreover, case studies do not allow new instructors to acquire only professional knowledge and techniques, but also an understanding of the relationship between order, regularity, and the chaos of reality. In addition, they serve as an opportunity to study universal trends, beliefs, and plans through learning why and how decisions are made in unique situations. Furthermore, case studies record and relate events that are not foreseen in the planning stages of the instruction scheme. Moreover, they showcase the difficulty of specific contexts: events arising suddenly, dilemmas arising that surpass the instructor's predictions and thoughts, the instructor's discoveries, and the feelings that appear along with these discoveries. Through this, new instructors study complexity by means of a stand-in experience as their first experience in these situations, while simultaneously working toward a secondary experience, where they learn how to interpret the first one. Subsequently, they move toward a tertiary experience, where they understand complexity abstractly and connect it with things that are related to them. New instructors can determine the decisions that are best in similar situations by searching for the causes of problems within the case studies and by being aware of the difficulty and perplexity that problems bring. In addition, they can study the duality of actions by becoming aware of the dangers and advantages apparent in approaches to dealing with a given problem. Furthermore, they can study how to make conjectures based on small clues and become motivated to teach. The above has demonstrated the efficacy of case studies in the formation of new instructors' capabilities. Therefore, one can argue that case studies that use theoretical models to improve the educational abilities of new nursing instructors should be promoted to improve their way of thinking and practical educational capabilities.

Studies 1 and 2 provide a new understanding of how the perceptions of new nursing instructors can be changed, namely, how they may be able to acquire an instructors way of thinking and acting through case studies that use the clinical training instruction model. At many schools, new nursing instructors seek out the FD for support in educational practice. These studies have verified the efficacy of case studies as a method of reflection for professional educators.

According to Korthagen et al. (2014), the time required for new instructors to move from learning about teaching to being able to conduct a class as a true instructor is a long period, filled with many troubles and emotional ups and downs. During this period, the new instructors come face-to-face with realities, responsibilities, and complexities that they were previously unaware of in the classroom, resulting in a reality or transition shock. In short, it is a period during which new instructors face profound stress and difficult problems. Korthagen states that, during this period, new instructors lose the attitudes and understandings they obtained during their university education by accumulating in-school experiences. Briefly put, new instructors are unable to practice what they have learned about becoming an instructor. 
For clinical education, it is critical to understand students' current learning conditions. This is required to understand the clinical situation and the patient's condition as well as to select a method after inferring what will lead to the student's edification in each scenario. The descriptions of the new instructors show us a focus on students' behavior and statements and a lack of descriptions concerning "perspectives on instruction" and students' "perspectives on learning", such as on the failure to record educational or learning goals (instead, only impressions were given, such as those concerning students' proper behavior). We can also see a fragmentary understanding of students' behavior from the lack of descriptions of inferences. This result coincides with Sato's research findings on new instructors' thoughts and procedures, where new instructors expressed fragmentary impressions of on-site educational practices and were unable to approach problems with typical issues of contextual meaning, as well as where investigations of meaning inherent to instruction did not appear due the fact that problem identification was conducted through the application of general standards and commonplace conceptions (Sato et al. 1990). As a result, new instructors are then unable to apply techniques and expertise isolated from a specific situation or to comprehend complex situations. Furthermore, instructors understood students' behavior only in terms of fragmentary facts and impressions, and they were unable to link behavior in other scenarios to that specific situation. This is a consequence of a common characteristics among new instructors; namely, not understanding educational practice in educational contexts. Therefore, it is necessary for new instructors to practice thinking along the lines of contextual education, such as reading educational contexts and students' learning. Furthermore, when looking at recollections of the facts that the new instructors focused on, we can observe that "proper behavior" and "scheduled time" were recalled in relation to student behavior. We can say that this way of thinking results from Akita's mistaken and simplistic conceptions (2009). This way of thinking results from the inability to use educational methods and knowledge that has already been learned. Korthagen et al. (2014) says that students that commence the study of teaching are bound by their preconceptions about education. Moreover, he states that these preconceived views do not match the theory of becoming a teacher that is taught in educational programs and that this theory is ineffective in changing these preconceived views. Therefore, new teachers will not necessarily be able to convert theory into practice in educational sites just because they have studied theory and ideas during their training. In short, one could argue that the inability to hold scientific views of instruction and learning (based on theory) is characteristic of new instructors. This study suggests that new nursing instructors are unable to apply in practice what they have studied, as is the case with new instructors in general. Difficulties arise for new instructors because they have not constructed an approach to reading situations and they are unable to apply what they have already learned to practical settings.

Through these case studies, which used the clinical training instruction model, with new nursing instructors and experienced instructors working 
together, the new nursing instructors "reflected objectively on themselves and were made aware of their positions and perspectives". They became aware of a "change of focus from what students cannot do to a focus on what causes this inability", such as regarding their "understanding of the necessity to comprehend individuals and focus on students' experiences that caused their actions". They revealed a "changed perspective from that of a nurse to that of a teacher who is training nurses". Furthermore, the case studies resulted in the new instructors "reflecting on themselves as instructors, becoming aware of their own deficiencies, and understanding how to deal with difficult cases". They also came to understand students who were the target of education, such as in their "understanding of the necessity to think about the meaning of students' actions in accordance with the nursing model to convey the joy of nursing to students" and in how they "began to instruct with focus on students' perceptions and individuality". They also discovered concrete methods for and the necessity of conveying educational nursing information, as in their "being conscious of their intentional and planned management of the training and how they were able to manifest this in the teaching material".

Underlying this ability to induce change in the ways of understanding educational practices and new instructors' perspectives is the understanding that new nursing instructors are unable to observe these aspects or do not think independently. This is revealed in their responses to experienced instructors' questions and by their "understanding of the necessity to comprehend individuals and focus on students' experiences that caused their actions". They realized that thoughts and actions are incongruous in such cases. Through repeating these kinds of case studies, they learned methods for problem solving in educational contexts, such as by "reflecting on themselves as instructors, becoming aware of their own deficiencies, and understanding how to deal with difficult cases". Furthermore, through achieving the ability to understand the students' way of thinking and actions, and learning methodologies to deal with difficult cases, new instructors understood their own practices and "were conscious of their intentional and planned management of the training and could manifest this in the teaching material". The new instructors have truly achieved new perspectives on instruction and learning. Furthermore, the new instructors reflected on their "understanding of the information that they studied during the instructor training course", which was centered on their abilities. These reflections show that they applied the theory that they had studied to educational settings. Moreover, it indicates that they are in the midst of acquiring the necessary knowledge and skills for practical educational settings. Hence, case studies are an effective method of improving practical educational capabilities, for example, when applying educational theory to practice and helping new instructors to acquire a teacher's perspective and an understanding of their students. 


\section{Conclusion}

New nursing instructors, although clinically experienced as nurses, had a limited understanding of phenomena related to students who would be the target of their instruction. Furthermore, in this study, it was clarified that new instructors had an inadequate understanding of their students' learning.

Case studies are promoted in the education field as a way to improve instructions' educational abilities (Akita 2009, Korthagen et al. 2014). The drawing up of cases by new instructors provides an opportunity for them to reflect on their actions and elucidates how new instructors perceive clinical situations. By performing these case studies together with experienced instructors, those presenting their cases can be questioned about the information that is necessary to understand the problems that arise. Through this questioning, new instructors are able to seek out knowledge of situations that they cannot comprehend or describe. In case studies, these facts are demonstrated through the perspectives of both beginners and experienced instructors. Beginners learn about methods for understanding educational phenomena when their views on understanding educational phenomena are repeatedly questioned by experienced instructors, and when they learn about the methods that they use. In order to change new instructors' preconceptions or current views on education into educational concepts, not only the repetition of practice, but also coherent guidelines for education are needed.

We can assume that the clinical training instruction model will perform the role of coherent guideline for nursing education. The model can be said to support the acquisition of a nurse's perspective, thus serving as a tool for reflection.

Case studies do not allow new instructors to acquire only professional knowledge and techniques, but also an understanding of the relationship between order, regularity, and the chaos of reality. Furthermore, case studies record and relate events that are not foreseen in the planning stages of the instruction scheme. New instructors can study how to make conjectures based on small clues and become motivated to teach.

The above has demonstrated the efficacy of case studies in the formation of new instructors' capabilities. Therefore, one can argue that case studies that use theoretical models to improve the educational abilities of new nursing instructors should be promoted to improve their way of thinking and practical educational capabilities. In the future, it is necessary for us to increase the number of case study to be analyzed.

\section{Limitation}

There may have been selection bias because each participant attended a program of their choice (in the programs). 


\section{References}

Akita K (2009) The Movement towards Research of the Teacher Learning Process away from Teacher Education: The Change towards Research of Microeducational Practices. Transformative Pedagogy. Tokyo Seori-Shobo, pp. 45-75.

Bill C (2011) Lesson Study: Overview of the Lesson Study. Virginia: Stylus, pp. 11-28.

Ishida K (2010) Issues Based on the Research Literature for the Promotion of Faculty Development Intended for Beginner Teachers at Nursing Universities. Nursing Scientific Research 9: 10-18.

Ito R, Omachi Y (2009) Sources of felt difficulties in nursing training instruction by new instructors at nursing universities. Nursing Education 50(5): 414-422.

Korthagen FAJ, Bob K, Bram L, Theo W (2014) Linking Practice and Theory: The Pedagogy of Realistic Teacher Education. London: Routledge, pp. 52, 61.

Ministry of Health, Labour and Welfare (2010) An Investigative Report on the State of Nursing Instructors, pp. 1-11. Retrieved from goo.gl/bJ2dCL.

Ogasawara H (1994) Perceptions of nurses and changes to those perceptions in the nursing process for difficult responses. Comprehensive Nursing Care 29(3): 3-14.

Sato M, Iwakawa N, Akita K (1990) Practical Thinking styles of Teachers: Comparing the Monitoring Processes of Experts with Novices. The faculty of the University of Tokyo, pp. 30, 177-108.

Schön D (1983) The Reflective Practitioner: How Professionals Think in Action. USA Cambridge: Basic Books. 4-20.

Tokumoto H (1998) The structure of the development process of recognition formed by nurses in case study group session. Chiba Academy of Nursing Science 4(1): $1-38$.

Tokutomo H (2013) Outcome of the teacher training course reinforcing nursing teacher competence: teaching skills developed through continuous case studies The Bulletin of Saitama Prefectural University 15: 35-42.

Usui H (1974) A Theory of Scientific Nursing (1st edn.). Tokyo: Japanese Nursing Association's Publishing Association, p. 81.

Usui H (1991b) Training for nursing methods through the module system. Tokyo: Gendaisha, p. 12.

Wazumi Y (1996) Mastering the Process of the Academic Methodology of Nursing Science. Chiba Academy of Nursing Science 2(1): 1-7.

Usui H (1991a) The Scientific Application of Nightingale's Theory. Tokyo: Gendaisha. Hakuho Anthology, Vol. 12.

Lin X, Schwartz DL, Hatano G (2005) Toward teachers' adaptive metacognition. Educational Psycholgist 40: 254-255. 
